\title{
Memory function in opioid-dependent patients treated with methadone or buprenorphine along with benzodiazepine: longitudinal change in comparison to healthy individuals Pekka Rapeli*1,2,3, Carola Fabritius ${ }^{2}$, Hely Kalska ${ }^{3}$ and Hannu Alho ${ }^{2,4}$
}

Address: ${ }^{1}$ Unit for Drug Dependence, Department of Psychiatry, Helsinki University Central Hospital, Helsinki, Finland, ${ }^{2}$ National Institute for Health and Welfare, Helsinki, Finland, ${ }^{3}$ Department of Psychology, Faculty of Behavioural Sciences, Helsinki, Finland and ${ }^{4}$ Research Unit of Substance Abuse Medicine, University of Helsinki, Helsinki, Finland

Email: Pekka Rapeli* - pekka.rapeli@hus.fi; Carola Fabritius - carola.fabritius@soster.hel.fi; Hely Kalska - hely.kalska@helsinki.fi; Hannu Alho - hannu.alho@thl.fi

* Corresponding author

Published: 17 April 2009

Substance Abuse Treatment, Prevention, and Policy 2009, 4:6 doi:10.1 186/1747-597X-4-6

This article is available from: http://www.substanceabusepolicy.com/content/4/1/6

(C) 2009 Rapeli et al; licensee BioMed Central Ltd.

This is an Open Access article distributed under the terms of the Creative Commons Attribution License (http://creativecommons.org/licenses/by/2.0), which permits unrestricted use, distribution, and reproduction in any medium, provided the original work is properly cited.
Received: 14 October 2008

Accepted: 17 April 2009

\begin{abstract}
Background: Opioid-substitution treatment (OST) for opioid dependence (OD) has proven effective in retaining patients in treatment and reducing illegal opiate abuse and crime. Consequently, the World Health Organization (WHO) has listed the opioid agonists methadone and buprenorphine as essential drugs for OD that should be available worldwide. In many areas of the world, OD is often associated with concomitant benzodiazepine (BZD) dependence and abuse, which complicates treatment. However, possible changes in the cognitive functioning of these patients are not well-known. The present study is the first to examine longitudinal stability of memory function in OST patients with BZD use, thus providing a new tool for health policy authorities in evaluating the usefulness of OST.
\end{abstract}

Methods: Within the first two months (TI) and between 6-9 months (T2) after OST admission, we followed the working memory, immediate verbal memory, and memory consolidation of 13 methadoneand 15 buprenorphine- or buprenorphine/naloxone-treated patients with BZD dependence or abuse disorder. The results were compared to those of fifteen normal comparison participants. All participants also completed a self-reported memory complaint questionnaire on both occasions.

Results: Both patient groups performed statistically significantly worse than normal comparison participants in working memory at time points $\mathrm{TI}$ and T2. In immediate verbal memory, as measured by list learning at $\mathrm{TI}$, patients scored lower than normal comparison participants. Both patient groups reported significantly more subjective memory problems than normal comparison participants. Patients with more memory complaints recalled fewer items at $\mathrm{T} 2$ from the verbal list they had learned at $\mathrm{TI}$ than those patients with fewer memory complaints. The significance of the main analyses remained nearly the same when the statistical tests were performed without buprenorphine-only patients leaving 12 patients to buprenorphine/naloxone group.

Conclusion: Working memory may be persistently affected in OST patients with BZD use. A high number of memory complaints among OST patients with BZD use may indicate memory consolidation impairment. These findings show that recovery of memory function in OD patients treated along with BZDs takes time, and their memory complaints may have practical relevance. 


\section{Introduction}

Opioid-substitution treatment with the full mu opioid receptor agonist methadone or the partial agonist buprenorphine is the most effective treatment for OD $[1,2]$. Follow-up studies of OST patients have shown consistently high retention in OST, fewer crimes, reduction in substance abuse, and improved health $[3,4]$. However, the psychosocial recovery of OD patients during treatment is still controversial. It has been stated that while opioid abuse and other problem behavior reduces during the OST, there is little research-based evidence for improvement if patient-centered indicators of quality of life are used [5]. While this critique underestimates the importance of reduction of the health hazards of OD, it also shows the shortage studies using objective measures of psychological functions. In order to meet this challenge, studying memory function of OD patients is an important element, because the patients often complain poor memory $[6,7]$. Therefore, in this longitudinal study memory function of OST patients was evaluated by tests and subjective memory questionnaire. Because in Finland most OD patients are prescribed benzodiazepines or abuse them from illegal sources $[7,8]$, we examined memory function of this clinically relevant majority.

Some studies have shown substantial memory deficits among OD patients in methadone treatment even after years of treatment $[9,10]$. Also, buprenorphine-treated patients may show poor memory function $[11,12]$. However, only two studies have examined the longitudinal stability of memory function during OST. In the seminal longitudinal study by Grevert et al., the memory performance of OST patients, of whom about one third tested positive for other drugs of abuse during the tests, was assessed three times within the first three months of treatment [13]. No baseline or subsequent differences between the methadone patients and a comparison group were seen in objective or subjective memory function. No significant correlations were seen between drug screen status and memory test results. However, as the patients performed the tests immediately before or after the methadone dose, that is, when their plasma concentration is known to be at the lowest level, short-term negative effects of high methadone concentrations may have been missed. In a more recent study by Gruber et al., the tests were done a few hours after the methadone dose [14]. The patients' memory performance was tested first within the first few weeks of OST and again after two months of treatment. Although $65 \%$ of the patients tested positive for any illicit use at the first test and $76 \%$ at the second test, the results showed a statistically significant improvement in verbal list learning among patients.

In our previous study, we found that both methadoneand buprenorphine/naloxone-treated patients in early OST performed worse than normal comparison partici- pants on a working memory task [15]. The verbal memory deficit was more pronounced in methadone-treated patients than in buprenorphine/naloxone-treated patients. Although the results partially favored buprenorphine/naloxone-treated patients, BZD co-medication that was common in both patient groups, may have affected the results. There are no longitudinal studies comparing the effects of OST drugs while patients use BZDs. However, there is some evidence for acute negative effects of opioid agonists on working memory in drug-naïve healthy volunteers and for chronic negative effects in pain patients $[16,17]$. The negative effects of BZDs on working memory and long-term memory are better - known, vary from small to moderate, and may last several months after cessation of use [18]. Of special interest is the study of Lintzeris et al., which found that in comparison to a placebo condition, methadone dose alone, or buprenorphine dose in combination with BZD diazepam impairs verbal recall in OST patients [19]. Given these findings suggesting memory deficits in OST patients using BZDs, we did a follow-up study of memory function in OD patients treated with methadone or buprenorphine (including buprenorphine/naloxone) along with BZDs. In order to control for the effects of repeated testing, a comparison group performed similar tests. Working memory, immediate verbal memory, and memory consolidation were examined. The participants also completed the Memory Complaint Questionnaire, which assesses subjective memory function [20].

We hypothesized that working memory function in both OST patient groups treated along with BZDs would be impaired relative to normal comparison participants in the first testing (T1) and would not show improvement. Second, we hypothesized that immediate verbal memory would be impaired relative to normal comparison participants at T1 and would not show improvement in OST patients also using BZDs. Third, we hypothesized that memory consolidation would be impaired in OST patients. Finally, we hypothesized that among OST patients subjective and objective memory function would correlate negatively.

\section{Methods}

The study participants with OD were volunteers admitted for standard OST in the addiction clinics of the Helsinki area. Normal comparison participants were recruited from adult education centers and by word of mouth. All participants included in the study were between $18-50$ years of age and native Finnish speakers. For OST patients, additional inclusion criteria were OD diagnosis, BZD dependence or abuse diagnosis, start of OST during the last two months, and treatment of OD with methadone, buprenorphine, or buprenorphine/naloxone. We excluded participants with uncontrolled polysubstance abuse, acute alcohol abuse, or acute axis I psychiatric mor- 
bidity other than substance abuse related. We also excluded participants with severe brain injury, chronic neurological disease, history of other than substanceinduced psychoses, epileptic seizures, human immunodeficiency virus (HIV) infection, pregnancy, or primary cognitive deficit. For these purposes, psychiatric interviews by clinical psychiatrist were conducted for all participants, and diagnostic criteria from the Diagnostic and Statistical Manual of Mental Disorders (DSM-IV) were applied $[21,22]$.

Each OST participant eligible for our study was screened by urine sample for substance abuse on the day of testing and at least once in the preceding month. One third of normal comparison participants were chosen at random for screening for drug of abuse. Participants showing signs of current intoxication, ongoing binge on any substance of abuse, and those with any extra psychoactive drug dose within $24 \mathrm{~h}$ were all excluded. According to these criteria 13 methadone- and 15 buprenorphine/naloxone- or buprenorphine-treated patients and 15 normal comparison participants could be studied twice. This represents $59 \%$ of volunteer methadone patients at $\mathrm{T} 1,52 \%$ of buprenorphine patients (including both products), and $79 \%$ of normal comparison participants. Eight volunteer patients were excluded from the study based on their substance abuse before the test. Fourteen eligible patients and four normal comparison participants dropped out of the study between $\mathrm{T} 1$ and $\mathrm{T} 2$. At T1, 23\% of the methadone patients and $40 \%$ of the buprenorphine patients were tested in inpatient settings. At T2, none of the methadone patients and $13 \%$ of the buprenorphine patients were tested in inpatient settings.

\section{Ethics}

The study was approved by the independent Hospital District of Helsinki and Uusimaa Ethical Committee (permission 90/2001). The study was conducted in accordance with the 1964 Declaration of Helsinki. All patients were required to be able to read and understand the patient information sheet and sign the informed consent form. All participants were free to discontinue participation in the study whenever they wanted. The participants were reimbursed with $€ 40$ if they attended all study visits.

\section{Procedure}

Cognitive testing was done three to six hours after administration of the opioid-substitution drug. During this time the drug plasma concentration is at its peak [23]. At T1, the methadone patients were given, under supervision on the morning of the test day, a mean dose of $72.9 \mathrm{mg}$ ( $S D$ $=35.2$ ) of liquid methadone, range $35-150 \mathrm{mg}$. At T2, the respective values for methadone were $125.7 \mathrm{mg}(S D=$ 35.8 ), range $70-180 \mathrm{mg}$. At $\mathrm{T} 1$, the buprenorphine patients were given, under supervision on the morning of the test day, a mean dose of $17.3 \mathrm{mg}(S D=3.6)$ of sublingual buprenorphine, range $12-24 \mathrm{mg}$. At T2, the respective values were $22.7 \mathrm{mg}(S D=2.9)$, range $16-28 \mathrm{mg}$. Rise of the dose was statistically significant in both groups (Wilcoxon's Signed Ranks test, exact (2-sided) $p=0.001$ in both groups). In the buprenorphine group, $80 \%$ of the patients were given buprenorphine/naloxone; thus, they were also given sublingual naloxone in a ratio of 1:4 together with their buprenorphine dose. Several studies have shown that among OD individuals sublingual naloxone has minimal if any interference with the opioid agonist effects of the buprenorphine [24-26]. Other prescribed psychoactive medications were given to the patients according to their clinical dose regimen. Table 1 describes the BZDs and their doses used within the 24hour period before the tests. In order to compare the BZD doses of the groups, all BZDs were converted to diazepam equivalent doses according to their known clinical potency [27]. Temazepam and midazolam doses were halved in order to account for their use as hypnotics on the night before testing. After this conversion, no statistically significant difference existed between the patient groups in their mean estimated diazepam equivalent dose at $\mathrm{T} 1$ or $\mathrm{T} 2$. There was no significant change between the T1 and T2 BZD doses within the groups. The diazepam equivalent dose at $\mathrm{T} 1$ was on average $26.2 \mathrm{mg}(S D=18.5)$ in the methadone group and at T2 $26.5(S D=10.0)$; in the buprenorphine group, the respective values were 27.7 (SD $=24.1)$ and $21.0(S D=11.1)$. In other types of psychoactive drugs there were no statistically significant changes between the test points.

\section{Memory tests}

Working memory refers to the limited capacity shortterm store that temporarily maintains information, which is lost without rehearsal [28]. It was assessed by the LetterNumber-Sequencing task from the Wechsler Memory Scale-third version (WMS-III) and by the computerized version of the Paced Auditory Serial Addition Task (PASAT) from the FORAMENRehab software package [2931].

Immediate verbal memory refers to immediate storage of verbally presented items in those situations that exceed the capacity of sensory-specific working memory stores. Typical examples of immediate verbal memory measures include recall of a list or story. Immediate verbal memory is thought to rely on both working and long-term memory stores. This concurrent activation of two memory stores has recently been experimentally confirmed [32]. Immediate verbal memory was assessed by two verbal memory tasks, a list learning and a story recall task: the Memory for Persons Data and The Logical Memory [29,33]. Both tasks were presented in modified versions. The details of these tasks are presented in our previous study [15]. 
Table I: Co-medications among patients used within the last $24 \mathrm{~h}$ before testing at TI and T2

\begin{tabular}{|c|c|c|c|c|}
\hline & \multicolumn{2}{|l|}{ Methadone $(n=13)$} & \multicolumn{2}{|c|}{ Buprenorphine or Buprenorphine/Naloxone $(n=15)$} \\
\hline & Proportion of patients & Dose, range & Proportion of patients & Dose, range \\
\hline Antidepressants (any), TI/T2 & $54 \% / 46 \%$ & & $40 \% / 53 \%$ & \\
\hline Citalopram TI & $8 \%$ & $40 \mathrm{mg}$ & - & - \\
\hline Citalopram T2 & - & - & $13 \%$ & $10 \mathrm{mg}$ \\
\hline Escitalopram TI & $8 \%$ & $5 \mathrm{mg}$ & - & - \\
\hline Escitalopram T2 & $8 \%$ & $10 \mathrm{mg}$ & - & - \\
\hline Doxepine TI & - & - & $13 \%$ & $75-100 \mathrm{mg}$ \\
\hline Doxepine T2 & $8 \%$ & $50 \mathrm{mg}$ & $20 \%$ & $25-100 \mathrm{mg}$ \\
\hline Fluoxetine TI & $15 \%$ & $20-30 \mathrm{mg}$ & - & - \\
\hline Fluoxetine T2 & $8 \%$ & $40 \mathrm{mg}$ & - & - \\
\hline Milnacipran TI & - & - & - & - \\
\hline Milnacipran T2 & - & - & $7 \%$ & $50 \mathrm{mg}$ \\
\hline Mirtazapine TI & $25 \%$ & $15-30 \mathrm{mg}$ & - & - \\
\hline Mirtazapine T2 & $25 \%$ & $30 \mathrm{mg}$ & $7 \%$ & $30 \mathrm{mg}$ \\
\hline Paroxetine TI & $8 \%$ & $50 \mathrm{mg}$ & $7 \%$ & $50 \mathrm{mg}$ \\
\hline Paroxetine T2 & - & - & $13 \%$ & $40 \mathrm{mg}$ \\
\hline Sertraline TI & - & - & $7 \%$ & $50 \mathrm{mg}$ \\
\hline Sertraline T2 & - & - & $7 \%$ & $50 \mathrm{mg}$ \\
\hline Trimipramine TI & - & - & - & - \\
\hline Trimipramine T2 & $8 \%$ & $150 \mathrm{mg}$ & - & - \\
\hline Venlafaxine TI & - & - & $13 \%$ & $75 \mathrm{mg}$ \\
\hline Venlafaxine T2 & - & - & $7 \%$ & $75 \mathrm{mg}$ \\
\hline $\begin{array}{l}\text { Anxiolytics, sedatives and } \\
\text { hypnotics: Benzodiazepines (any), } \\
\text { TI/T2 }\end{array}$ & $87 \% / 100 \%$ & & $93 \% / 100 \%$ & \\
\hline Alpratzolam TI & - & - & $13 \%$ & $\mathrm{I}-2 \mathrm{mg}$ \\
\hline Alpratzolam T2 & - & - & $13 \%$ & $\mathrm{I}-2 \mathrm{mg}$ \\
\hline Clonazepam TI & - & - & $13 \%$ & $2-5 \mathrm{mg}$ \\
\hline Clonazepam T2 & - & - & - & - \\
\hline Diazepam TI & $46 \%$ & $10-55 \mathrm{mg}$ & $47 \%$ & $10-40 \mathrm{mg}$ \\
\hline Diazepam T2 & $38 \%$ & $15-30 \mathrm{mg}$ & $67 \%$ & $5-30 \mathrm{mg}$ \\
\hline Oxazepam TI & $31 \%$ & $60-120 \mathrm{mg}$ & $33 \%$ & $30-90 \mathrm{mg}$ \\
\hline Oxazepam T2 & $46 \%$ & $15-60 \mathrm{mg}$ & $20 \%$ & $55-60 \mathrm{mg}$ \\
\hline MidazolamTIa & - & - & - & - \\
\hline MidazolamT2a & - & - & $7 \%$ & $30 \mathrm{mg}$ \\
\hline Temazepam Tla & $31 \%$ & $20 \mathrm{mg}$ & $13 \%$ & $20 \mathrm{mg}$ \\
\hline Temazepam T2a & $15 \%$ & $20-40 \mathrm{mg}$ & $13 \%$ & $20-40 \mathrm{mg}$ \\
\hline
\end{tabular}


Table I: Co-medications among patients used within the last $24 \mathrm{~h}$ before testing at TI and T2 (Continued)

\begin{tabular}{|c|c|c|c|c|}
\hline $\begin{array}{l}\text { Non-benzodiazepine hypnotics } \\
\text { (any), TI/T2 }\end{array}$ & $15 \% / 8 \%$ & & $20 \% / 7 \%$ & \\
\hline Zolpidem Tla & - & - & - & - \\
\hline Zolpidem T2a & $8 \%$ & $10 \mathrm{mg}$ & $7 \%$ & $10 \mathrm{mg}$ \\
\hline Zopiclone TIa & $15 \%$ & $7.5 \mathrm{mg}$ & $20 \%$ & $7.5-15 \mathrm{mg}$ \\
\hline Zopiclone $\mathrm{T} 2^{\mathrm{a}}$ & $8 \%$ & $7.5 \mathrm{mg}$ & $7 \%$ & $7.5 \mathrm{mg}$ \\
\hline Neuroleptics (any), TI/T2 & $20 \% / 8 \%$ & & $7 \% / 7 \%$ & \\
\hline Levomepromazine TI & - & - & - & - \\
\hline Levomepromazine T2 & $8 \%$ & $50 \mathrm{mg}$ & - & - \\
\hline Quetiapine TI & $20 \%$ & $50-300 \mathrm{mg}$ & $7 \%$ & $300 \mathrm{mg}$ \\
\hline Quetiapine T2 & - & - & $7 \%$ & $150 \mathrm{mg}$ \\
\hline Rispiderone TI & - & - & - & - \\
\hline Rispiderone T2 & $8 \%$ & - & - & - \\
\hline $\begin{array}{l}\text { Substance abuse withdrawal } \\
\text { symptom or (non-opioid) pain } \\
\text { relievers (any), TI/T2 }\end{array}$ & $42 \% / 25 \%$ & & $40 \% / 13 \%$ & \\
\hline Disulfiram T2 & - & - & - & - \\
\hline Disulfiram T2 & $8 \%$ & $600 \mathrm{mg}$ & - & - \\
\hline Hydroxyzine TI & $25 \%$ & $25-200 \mathrm{mg}$ & $27 \%$ & $75-200 \mathrm{mg}$ \\
\hline Hydroxyzine T2 & $8 \%$ & $50 \mathrm{mg}$ & $7 \%$ & $100 \mathrm{mg}$ \\
\hline Ibuprofen TI & $8 \%$ & $600 \mathrm{mg}$ & $7 \%$ & $400 \mathrm{mg}$ \\
\hline Ibuprofen T2 & - & - & $7 \%$ & $600 \mathrm{mg}$ \\
\hline Lofexidine TI & $8 \%$ & $0,2 \mathrm{mg}$ & $20 \%$ & $0.2-0.6 \mathrm{mg}$ \\
\hline Lofexidine T2 & - & - & - & - \\
\hline Metoclopramide TI & $8 \%$ & $10 \mathrm{mg}$ & - & - \\
\hline Metoclopramide T2 & - & - & - & - \\
\hline Naproxen TI & $8 \%$ & $500 \mathrm{mg}$ & - & - \\
\hline Naproxen T2 & - & - & - & - \\
\hline Propranol TI & $8 \%$ & $20 \mathrm{mg}$ & - & - \\
\hline Propranol T2 & - & - & - & - \\
\hline Valproate TI & $8 \%$ & $1000 \mathrm{mg}$ & $20 \%$ & $500-1000 \mathrm{mg}$ \\
\hline Valproate T2 & - & - & $7 \%$ & $100 \mathrm{mg}$ \\
\hline
\end{tabular}

a Used as a hypnotic on the night before testing.

b Used for anxiolysis.

Memory consolidation refers to the storage and consolidation of memory traces. Early memory consolidation lasts from minutes to hours and late memory consolidation from weeks to years; these rely partly on separate neural processes [34,35]. Early memory consolidation was assessed by the percentage of the Logical Memory and Memory for Persons Data items successfully recalled by free recall after a short delay (30 min). Late memory consolidation was assessed by free recall of the Memory for Persons Data items at T2, which occurred after at least four and on average six, months after initial learning. Partici- pants were further asked to rate the certainty of their answers after the long delay. This may give additional information about the memory processes the participants are employing [36]. If the participant gave the right answer, it was asked if he/she was certain that he/she actually remembered the answer or if he/she only felt he/she knew the answer but was not certain about it. In the case of "felt" or no answer, three nearly identical alternatives were given, one of them being correct. After the participant gave his/her choice, he/she was asked if he/she remembered, felt, or just guessed the answer. 
Subjective memory functioning was assessed by the Finnish version of the Memory Complaint Questionnaire, the MCQ [20]. In the MCQ, the participant is asked how his/ her memory now functions compared to when he/she was younger. Several answers are given, using a Likert-type scale, describing how well memory functions in everyday tasks (remembering persons, things, news, shopping list items, etc.). A high score indicates subjective memory impairment.

\section{Statistical Analysis}

Overall group differences in memory performance at T1 and T2 were tested for statistical significance using multiple planned analysis of covariance (ANCOVA) with years of education and verbal IQ estimate as covariates. Although there were no statistically significant differences between the groups in the verbal IQ, it was used as a covariate because it is known to affect memory performance in tasks with verbal content [37]. ANCOVA was followed, when appropriate, by pairwise group comparisons using normal comparison group as a reference group. The Holm's sequential Bonferroni procedure was used to control for Type I error across the pairwise comparisons [38]. In all analyses, statistical significance was set at 0.05 (twotailed). In the Memory for Persons Data, the data were highly skewed due to a ceiling effect in the initial learning and recall at T1. At T2, the Memory for Persons Data for delayed recall was skewed because of small variance. Because of these violations of the assumptions of parametric testing, we analyzed these conditions by KruskalWallis ANOVAs, which were followed, when appropriate, by pairwise Mann-Whitney $U$ tests. In order to confirm the validity of combining buprenorphine/naloxone and buprenorphine-only patients, the ANCOVAs and ANOVAs were also performed with buprenorphine/naloxone patients $(\mathrm{n}=12)$. The cross-sectional MCQ scores and the MCQ T2 differences between high vs. low score groups were analyzed by $t$-tests or Mann-Whitney $U$ tests. Correlations between the MCQ values and cognitive variables were analyzed by Pearson's product moment correlation or Spearman's rho correlations depending on the normality of the variables. Correlations of at least .35 will be reported. The statistical significance of correlations was determined by using the Holm-Bonferroni procedure.

Longitudinal changes were analyzed by repeated measures ANCOVA using education and VIQ as a covariates and the comparison group as a reference group. All statistical analyses were performed using SPSS statistical software, version 15.0, with the exception of the effect size calculations. For this purpose, an effect size calculator provided by Durham University, UK was employed $[39,40]$; and the Cohen's d values were corrected by Hedge's correction for small sample bias.

\section{Results \\ Study demographics}

Table 2 shows the comparisons of demographic variables of each group. The group difference in verbal intelligence (Verbal IQ) was statistically non-significant even though the comparison group had more education than the patient groups. There were no significant differences between the OST groups in history of substance abuse, duration of OST, or the prevalence of psychiatric co-morbidity. Personality disorder diagnoses were common in both patient groups. Buprenorphine was the main opioid of abuse before the OST admission in both groups. Among patients, no major change in the number of nonopioid substances abused during the recent month before the T1 or T2 testing was seen during the study period.

\section{Group comparisons at TI}

In Table 3, an overview of unadjusted memory test results at both test points is presented together with statistical comparisons for years of education and verbal IQ adjusted values, whenever adjusting was possible. In working memory tests, the methadone patients were inferior to controls in the PASAT, but in the Letter-Number Sequencing the group difference remained non-significant. The buprenorphine patients were inferior to normal comparison participants on the both of the working memory tests. In immediate verbal memory as measured by the first learning trial of the Memory for Persons Data, both patient groups performed significantly worse than normal comparison group. In early memory consolidation as measured by short-term retention of percentages of the Logical Memory and the Memory for Persons Data items, no significant group differences emerged. The statistical significance of the analyses remained the same when the analyses outlined in the Table 3 were done with buprenorphine/naloxone patients $(\mathrm{n}=12)$ instead of combining the buprenorphineonly and buprenorphine/naloxone patients. Statistically significant values of overall group effects were, in order, The Letter-Number Sequencing, The PASAT, the first trial of the Memory for Persons Data, and the MCQ $(F(2,35)=3.63$, $p=0.009 ; F(2,35)=9.57, p<0.001 ; X^{2}(2, N=40)=7.99$, exact $p=0.018 ; X^{2},(2, N=40)=11.83$, exact $\left.p=0.004\right)$. After this, pairwise analyses between the buprenorphine/ naloxone and normal comparison groups were performed. In the Letter-Number Sequencing the pairwise group comparison was statistically non-significant $(t(26)=2.67, p=$ $0.065)$. In the PASAT and in the first trial of the Memory Persons Data, the buprenorphine/naloxone group showed worse performance than the normal comparison group $(t$ $(26)=4.71, p=0.00$; Mann-Whitney $U=45.50$, exact $p=$ 0.028 , respectively). In the MCQ, the buprenorphine/ naloxone patients reported more memory complaints than the comparison participants (Mann-Whitney $U=26.00$, exact $p=0.004$ ). 
Table 2: Group demographics

\begin{tabular}{|c|c|c|c|c|}
\hline & $\begin{array}{l}\text { Methadone } \\
(n=13)\end{array}$ & $\begin{array}{l}\text { Buprenorphine or } \\
\text { Buprenorphine/Naloxone } \\
(n=\mid 15)\end{array}$ & $\begin{array}{l}\text { Normal Comparison } \\
(n=15)\end{array}$ & $\begin{array}{l}\text { Group comparison } \\
\text { p-values }\end{array}$ \\
\hline \multirow[t]{3}{*}{ Age, mean of years at TI (SD) } & $29.2(6.8)$ & $27.7(6.8)$ & $28.7(9.6)$ & $M$ vs. $B N, p=0.99$ \\
\hline & & & & M vs. NC, $p=0.99$ \\
\hline & & & & BN vs. NC, $p=0.99$ \\
\hline \multirow[t]{3}{*}{ Sex: females/males } & $7 / 6$ & $4 / 11$ & $8 / 7$ & $M$ vs. $B N, p=0.14$ \\
\hline & & & & $M$ vs. NC, $p=0.98$ \\
\hline & & & & BN vs. $N C, p=0.14$ \\
\hline \multirow[t]{3}{*}{ Verbal intelligence, Mean $^{\mathrm{b}}(S D)$} & $100.6(11.4)$ & $99.4(9.3)$ & I04.I (9.6) & $M$ vs. $B N, p=0.99$ \\
\hline & & & & $M$ vs. $N C, p=0.74$ \\
\hline & & & & BN vs. NC, $p=0.63$ \\
\hline \multirow[t]{3}{*}{ Education, mean of years $(S D)$} & $10.1(1.2)$ & $10.5(2.0)$ & $12.6(1.3)$ & $M$ vs. $\mathrm{BN}, p=0.54$ \\
\hline & & & & $M<N C^{* * *}, p<0.001$ \\
\hline & & & & $\mathrm{BN}<\mathrm{NC} \mathrm{C}^{* *}, p=0.006$ \\
\hline \multicolumn{5}{|l|}{$\begin{array}{l}\text { Opioid of abuse used within last } \\
\text { month at TI }\end{array}$} \\
\hline Buprenorphine & $85 \%$ & $100 \%$ & - & $M$ vs. $B N, p=0.48 c$ \\
\hline Heroin & $15 \%$ & $0 \%$ & & \\
\hline \multicolumn{5}{|l|}{$\begin{array}{l}\text { Other substances of abuse used within } \\
\text { last month at } \mathrm{TI} \text { and } \mathrm{T} 2\end{array}$} \\
\hline Alcohol (heavy use) d & $15 \% / 15 \%$ & $13 \% / 7 \%$ & $7 \% / 7 \%$ & $\begin{array}{l}\text { M vs. BN vs. NC (TI/T2), } \\
p=0.99 c / 0.99 c\end{array}$ \\
\hline Amphetamine & $8 \% / 8 \%$ & $13 \% / 7 \%$ & - & $\begin{array}{l}\text { M vs. BN vs. NC (TI/T2) } \\
p=0.99 c / 0.99 c\end{array}$ \\
\hline Benzodiazepine, any Use & $100 \% / 100 \%$ & $100 \% / 100 \%$ & $0 \% / 0 \%$ & $\begin{array}{l}M \& B N>N C * * *(T I / T 2) \\
p<0.00 I c / p<0.00 \mid c\end{array}$ \\
\hline Benzodiazepine, extra doses & $38 \% / 38 \%$ & $42 \% / 33 \%$ & - & $\begin{array}{l}M \text { vs. } B N(T I / T 2) \\
p=0.62 / p=0.78 \mathrm{c}\end{array}$ \\
\hline Cannabis & $31 \% / 31 \%$ & $40 \% / 27 \%$ & - & $\begin{array}{l}M \text { vs. } \mathrm{BN}(\mathrm{Tl} / \mathrm{T} 2) \\
p=0.83 \mathrm{c} / 0.84 \mathrm{c}\end{array}$ \\
\hline Nicotine (daily use) & $100 \% / 100 \%$ & $100 \% / 100 \%$ & $33 \% / 33 \%$ & $\begin{array}{l}M \& B N>N C^{* * *}(\mathrm{TI} / \mathrm{T} 2) \\
p<0.001 c / p<0.001 \mathrm{c}\end{array}$ \\
\hline $\begin{array}{l}\text { Duration of OST in the day of testing } \\
\text { at TI, Mean of days (SD) }\end{array}$ & $21(14)$ & $19(12)$ & - & $M$ vs. $B N, p=0.69$ \\
\hline $\begin{array}{l}\text { Duration of OST on the day of testing } \\
\text { at T2, Mean of days (SD) }\end{array}$ & $213(25)$ & $224(17)$ & - & $M$ vs. $B N, p=0.15$ \\
\hline
\end{tabular}

\begin{tabular}{|c|c|c|c|c|}
\hline \multicolumn{5}{|c|}{$\begin{array}{l}\text { Participants with other dependence or } \\
\text { abuse diagnosis at } \mathrm{Tl}\end{array}$} \\
\hline Alcohol & $0 \%$ & $0 \%$ & $0 \%$ & M vs. $B N$ vs. NC, $p=0.99 c$ \\
\hline Amphetamine & $0 \%$ & $0 \%$ & - & $M$ vs. $B N, p=0.99 c$ \\
\hline Benzodiazepine & $100 \%$ & $100 \%$ & - & $M$ vs. $B N, p=0.99 c$ \\
\hline Cannabis & $15 \%$ & $20 \%$ & - & $M$ vs. $B N, p=0.99$ \\
\hline \multirow[t]{3}{*}{ Nicotine } & $100 \%$ & $100 \%$ & $33 \%$ & $M$ vs. $B N, p=0.99 c$ \\
\hline & & & & $M$ vs. $N C, p=0.13 c$ \\
\hline & & & & BN vs. NC, $p=0.12^{c}$ \\
\hline \multirow{3}{*}{$\begin{array}{l}\text { Participants with any DSM-IV axis I } \\
\text { diagnosis at } \mathrm{TI}\end{array}$} & $15 \%$ & $20 \%$ & $0 \%$ & M vs. $\mathrm{BN}, p=0.99 c$ \\
\hline & & & & Mvs. NC, $p=0.2 \mathrm{Ic}$ \\
\hline & & & & BN vs. NC, $p=0.22^{c}$ \\
\hline
\end{tabular}


Table 2: Group demographics (Continued)



\section{Group comparisons at T2}

At T2, both patient groups were inferior to normal comparison group in working memory tests. In immediate verbal memory assessed by the immediate recall of the Logical Memory items, no significant group differences were seen. In early memory consolidation assessed by the Logical Memory short-term retention percentage, group differences were not significant. In late memory consolidation assessed by the Memory for Persons Data free recall or recognition retention percentages after at least four months' delay, there were no group differences. Again, dropping buprenorphine-only patients from the buprenorphine group did not change the statistical significance of the overall ANOVAs or ANCOVAs. Significance values of overall group effects were, in order, the LetterNumber Sequencing, The PASAT, and the MCQ $(F(2,35)$ $=3.82, p=0.032,\left(F(2,35)=7.52, p=0.02,\left(X^{2},(2, N=\right.\right.$ $40)=15.91$, exact $p<0.001)$. Pairwise comparisons between the buprenorphine/naloxone and normal comparison groups favored the comparison group in both working memory tasks: the Letter-Number Sequencing and The PASAT, respectively $(t(26)=2.21, p=0.03 ; t(26)$ $=3.33, p=0.002)$. In the MCQ, the buprenorphine/ naloxone patients reported more memory complaints the normal comparison participants (Mann-Whitney $U=$ 29.50 , exact $p=0.004$ ).

Interestingly, total "black-outs" in long delay free recall were rare. Only one methadone patient, two buprenorphine patients, and one comparison participant could not recall any items from the Memory for Persons Data in this condition. From Figure 1, which shows lines for cumulative percentages, it can be seen that about $50 \%$ of the normal comparison participants and buprenorphine patients could recall at least 4 items out of 15 correctly, while the corresponding score was 2 items among the methadone patients. When asked about the certainty of their answers, the patients were non-significantly more certain than the normal comparison participants that they actually remembered, not just felt, the correct answers they gave. On average, methadone-treated patients said that they surely remembered a mean of $64.1 \%$ of their correct free recall answers $(S D=38.8)$. In the buprenorphine group the corresponding figure was $67.2 \%(S D=24.1)$ and in the normal comparison group $45.5 \%(S D=31.3)$. In the same vein, there were no significant group differences in certainty of recognized correct answers (data not shown). Both patient groups again reported significantly more memory complaints in the MCQ.

\section{Correlations between subjective and objective memory functions among the patients}

The highest correlation between subjective MCQ score and the objective memory tests completed by the OST patients at T1 was - .38 for the Logical Memory retention percent after short delay (30 min). However, after correction for multiple comparisons, this moderate correlation was statistically non-significant. The correlation between the MCQ score at T1 and the long delay free recall of the Memory for Persons Data items at T2, that is, at least four months after initial learning, was -.58 and statistically significant, $p=0.028$. This relationship is depicted in Figure 1. At T2, two moderate correlations between subjective MCQ score at T2 and objective memory performance of the patients were seen: - .40 for long delay free recall of the Memory for Persons Data items and - .39 for the PASAT. However, after correction for multiple comparisons these were no longer statistically significant. In order to explore how the OST patients with high MCQ scores at the stabilized phase (T2) are different from those with low MCQ scores, the patient group was divided into high vs. low memory complaints groups using the T2 MCQ median score as the cut-off. Patients with scores of 26 or more at T2 made up the high memory complaints group 
Table 3: Group comparisons of memory functions at TI and T2

\begin{tabular}{|c|c|c|c|c|c|c|}
\hline Domain or Test & $\begin{array}{l}\text { Methadone } \\
(n=13)\end{array}$ & $\begin{array}{l}\text { Buprenorphine or } \\
\text { Buprenorphine/ } \\
\text { Naloxone } \\
(n=15)\end{array}$ & $\begin{array}{l}\text { Normal } \\
\text { Comparison } \\
(n=15)\end{array}$ & Group effect & $\begin{array}{l}\text { Statistical com- } \\
\text { parisons } \\
\text { between normal } \\
\text { comparison and } \\
\text { patient groups } \\
\text { using years of } \\
\text { education and } \\
\text { VIQ adjusted } \\
\text { scores, when- } \\
\text { ever possibleb }\end{array}$ & $\begin{array}{l}\text { Effect sizes, } \\
\text { whenever } \\
\text { possible }\end{array}$ \\
\hline & $M(S D)$ & $M(S D)$ & $M(S D)$ & & & \\
\hline \multicolumn{7}{|l|}{$\begin{array}{l}\text { Working memory, } \\
\text { raw scores }\end{array}$} \\
\hline \multirow[t]{2}{*}{$\begin{array}{l}\text { WMS-III Letter-Number } \\
\text { Sequencing at } \mathrm{TI}\end{array}$} & $9.6(2.3)$ & $8.4(2.3)$ & I I.7 (3.2) & $\begin{array}{l}F(2,38)=4.57 \\
p=0.017^{*}\end{array}$ & $\begin{array}{l}t(27)=1 . .84, p= \\
0.074, M \text { vs. } N C= \\
n s\end{array}$ & $d=0.68$ \\
\hline & & & & & $\begin{array}{l}t(29)=3.02, p= \\
0.008, \mathrm{NC}>\mathrm{BN} * *\end{array}$ & $d=1.01$ \\
\hline \multirow[t]{2}{*}{$\begin{array}{l}\text { WMS-III Letter-Number } \\
\text { Sequencing at T2 }\end{array}$} & $8.6(2.1)$ & $9.2(2.3)$ & II.6 (2.9) & $\begin{array}{l}F(2,38)=4.19 \\
p=0.023 *\end{array}$ & $\begin{array}{l}t(27)=2.76, p= \\
0.018, N C>M^{*}\end{array}$ & $d=1.05$ \\
\hline & & & & & $\begin{array}{l}t(29)=2.39, p= \\
0.022, \mathrm{NC}>\mathrm{BN} *\end{array}$ & $d=0.83$ \\
\hline PASAT at TI & $31.4(9.2)$ & $31.8(10.7)^{a}$ & $46.7(9.4)$ & $\begin{array}{l}F(2,38)=9.84 \\
p=0.001 * * *\end{array}$ & $\begin{array}{l}t(27)=4.19, p< \\
0.001, N C>M * * *\end{array}$ & $d=1.43$ \\
\hline \multirow[t]{3}{*}{ PASAT at T2 } & $31.6(8.6)$ & $34.1(8.4)$ & $46.0(8.7)^{\mathrm{a}}$ & $\begin{array}{l}F(2,38)=7.15 \\
p=0.002 * *\end{array}$ & $\begin{array}{l}t(29)=3.70, p< \\
0.00 \mathrm{I}, \mathrm{NC}>\mathrm{BN}^{* * *}\end{array}$ & $d=1.54$ \\
\hline & & & & & $\begin{array}{l}t(27)=3.47, p= \\
0.002, N C>M^{* *}\end{array}$ & $d=1.42$ \\
\hline & & & & & $\begin{array}{l}t(29)=3.32, p= \\
0.002, \mathrm{NC}>\mathrm{BN}^{* *}\end{array}$ & $d=1.24$ \\
\hline
\end{tabular}

Immediate verbal

memory, raw scores

\begin{tabular}{|c|c|c|c|c|c|c|}
\hline $\begin{array}{l}\text { Memory for Persons } \\
\text { Data, first trial at } \mathrm{TI}\end{array}$ & $10.7(2.6)$ & $10.8(2.5)$ & $13.0(1.5)$ & $\begin{array}{l}\chi^{2}(2, N=43)= \\
8.91 \\
p=0.012 *\end{array}$ & $\begin{array}{l}U=43.0, p=0.011 \\
N C>M^{*} \\
U=51.5, p=0.020 \\
N C>B^{*}\end{array}$ & - \\
\hline $\begin{array}{l}\text { Memory for Persons } \\
\text { Data, sum of last two } \\
\text { trials }(\mathrm{TI})\end{array}$ & $14.9(0.2)$ & I4.6 (0.7) & $14.9(0.2)$ & $\begin{array}{l}\chi^{2}(2, N=43)= \\
2.75 \\
p=0.25\end{array}$ & - & - \\
\hline $\begin{array}{l}\text { WMS-III Logical } \\
\text { Memory, immediate free } \\
\text { recall (TI) }\end{array}$ & $12.9(2.4)$ & I5.I (4.3) & $16.3(3.6)$ & $\begin{array}{l}F(2,38)=1.90 \\
p=0.16\end{array}$ & - & - \\
\hline $\begin{array}{l}\text { WMS-III Logical } \\
\text { Memory, immediate free } \\
\text { recall (T2) }\end{array}$ & $14.2(3.1)$ & I4.I (3.3) & 16.3 & $\begin{array}{l}F(2,38)=1.25, \\
p=0.30\end{array}$ & - & - \\
\hline
\end{tabular}

\section{Memory}

consolidation,

percentages

\begin{tabular}{|c|c|c|c|c|}
\hline $\begin{array}{l}\text { WMS-III Logical } \\
\text { Memory, free recall after } \\
\text { short-delay ( } 30 \mathrm{~min})\end{array}$ & $91.4(15.3)$ & $91.7(14.0)$ & $87.5(13.1)$ & $\begin{array}{l}F(2,38)=0.64, \\
P=0.94\end{array}$ \\
\hline
\end{tabular}

(TI) 
Table 3: Group comparisons of memory functions at TI and T2 (Continued)

\begin{tabular}{|c|c|c|c|c|c|c|}
\hline $\begin{array}{l}\text { WMS-III Logical } \\
\text { Memory, free recall after } \\
\text { short ( } 30 \text { min) delay } \\
\text { (T2) }\end{array}$ & $87.1(14.4)$ & $93.8(17.1)$ & $98.3(14.1)$ & $\begin{array}{l}F(2,38)=1.28 \\
p=0.29\end{array}$ & - & - \\
\hline $\begin{array}{l}\text { Memory for Persons } \\
\text { Data, free recall after } \\
\text { short delay }(30 \mathrm{~min}) \\
\text { (TI) }\end{array}$ & $92.8(7.9)$ & $98.2(6.1)$ & $98.7(3.1)$ & $\begin{array}{l}\chi^{2}(2, N=43)= \\
4.48 \\
p=0.11\end{array}$ & - & - \\
\hline $\begin{array}{l}\text { Memory for Persons } \\
\text { Data, free recall after } \\
\text { long delay } \\
(4-8 \mathrm{mo})(\mathrm{T} 2)\end{array}$ & $22.1(18.1)$ & $29.8(23.2)$ & $32.4(22.1)$ & $\begin{array}{l}\chi^{2}(2, N=43)= \\
I .54 \\
p=0.46\end{array}$ & - & - \\
\hline $\begin{array}{l}\text { Memory for Persons } \\
\text { Data, recognition after } \\
\text { long delay }(4-8 \mathrm{mo}) \\
\text { (T2) }\end{array}$ & $79.6(10.6)$ & $82.1(12.9)$ & $81.3(10.7)$ & $\begin{array}{l}F(2,38)=0.60 \\
p=0.55\end{array}$ & - & - \\
\hline
\end{tabular}

\begin{tabular}{|c|c|c|c|c|c|c|}
\hline \multicolumn{7}{|l|}{$\begin{array}{l}\text { Memory complaints, } \\
\text { raw score }\end{array}$} \\
\hline \multirow[t]{2}{*}{$\begin{array}{l}\text { The Memory Complaint } \\
\text { Questionnaire (TI) }\end{array}$} & $26.6(5.7)$ & $26.0(5.4)$ & $20.4(2.5)$ & $\begin{array}{l}\chi^{2}(2, N=43)= \\
\text { II.25 }\end{array}$ & $\begin{array}{l}U=39.0 \\
p=0.012, N C< \\
M^{*}\end{array}$ & - \\
\hline & & & & $p=0.004^{* *}$ & $\begin{array}{l}U=40.0, p=0.008 \\
N C<B N * *\end{array}$ & - \\
\hline \multirow[t]{2}{*}{$\begin{array}{l}\text { The Memory Complaint } \\
\text { Questionnaire (T2) }\end{array}$} & $25.6(3.2)$ & $24.5(6.7)$ & $20.4(1.5)$ & $\begin{array}{l}\chi^{2}(2, N=43)= \\
14.04\end{array}$ & $\begin{array}{l}U=16.5, p<0.001 \\
N C<M^{* * *}\end{array}$ & \\
\hline & & & & $p=0.00 I^{* * *}$ & $\begin{array}{l}U=49.0, p=0.015 \\
N C<B N *\end{array}$ & \\
\hline \multicolumn{7}{|c|}{$\begin{array}{l}\text { Note: PASAT }=\text { Paced Auditory Serial Addition Task; } \\
\text { WMS-III = Wechsler Memory Scale-third version. } \\
\text { BN = buprenorphine or buprenorphine/naloxone, } M= \\
\mathrm{a}=\text { Missing value of one participant was substituted by } \\
\text { **** = statistcally significant at level } b<000 \mathrm{*} \text {. }\end{array}$} \\
\hline
\end{tabular}

$(n=14)$ and those with scores up to 25 the low memory complaints group $(n=14)$. There were no statistically significant differences between the high and low memory complaint groups in demographics, substance abuse history, or treatment or medication variables. For cognitive variables, there were no significant differences between the groups except on the measure of Memory for Persons Data free recall, on which the respective means for the high and low groups were $16.7 \%(S D=16.7)$ and $35.7 \%$ $(S D=21.0) ;(t(27)=2.66, p=0.013)$. As can be seen from Figure 2, most of the patients classified as high memory complainers at T2 already had high MCQ scores at T1. Seventy-one percent of the high memory complainers at $\mathrm{T} 2$ complained of memory problems at T1 matching or exceeding the MCQ high memory complaints cut-off score of 26.

\section{Longitudinal changes}

In the first working memory task, the Letter-Number Sequencing, methadone-treated patients' performance seemed to deteriorate from $\mathrm{T} 1$ to $\mathrm{T} 2$ as shown by a decrease in their raw scores. On the other hand, they seemed to improve in immediate verbal memory performance. Opposite trends were seen in the buprenorphine group. However, no significant group by time interactions emerged.

\section{Discussion}

The main finding of this longitudinal study is the persistence of the working memory deficit in OD patients treated with methadone or buprenorphine along with BZDs. At $\mathrm{T} 1$, the buprenorphine patients were inferior to normal comparison participants in both working memory tests; and the methadone patients performed worse than normal comparison participants at the second working memory task, the PASAT. At T2, both patient groups were impaired relative to a normal comparison group on both working memory tests. The working memory tests used in this study have both been used also earlier in opioidrelated neuropsychological studies. In an earlier study by Verdejo-Garcia et al., minimum 15 days abstinent heroin abusers outperformed methadone-treated OST patients 


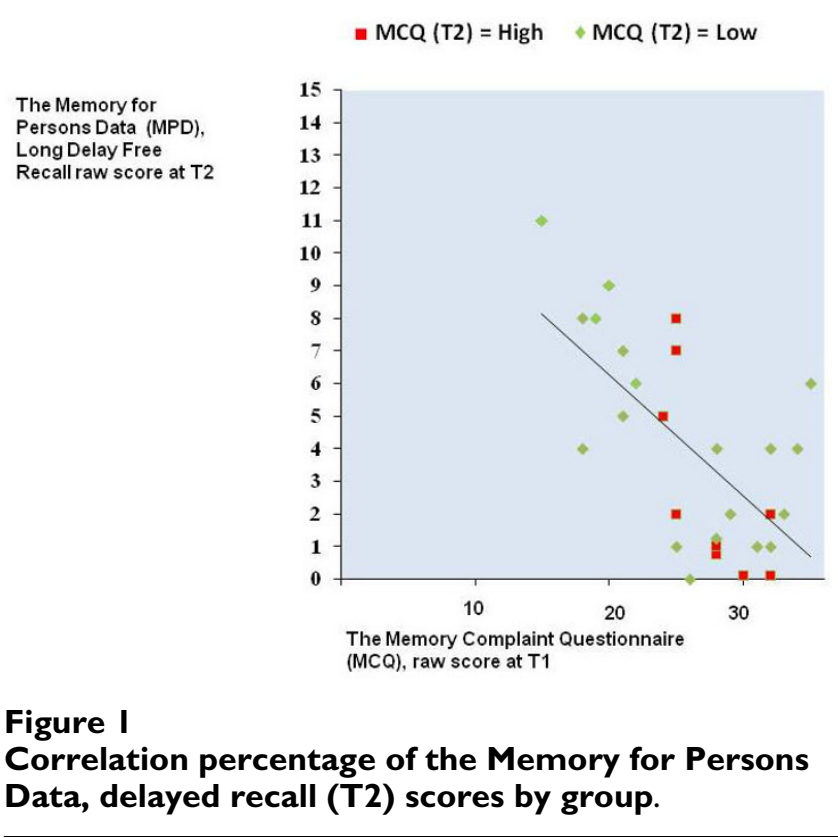

on our first working memory measure, the Letter-Number Sequencing [41]. In a study by Mintzer and Stitzer, methadone-treated OST patients performed worse than a wellmatched normal comparison group on a two-back working memory task closely resembling the PASAT [42]. The evidence for opioid agonist effects is not, however, unambiguous because in both of these studies, the OST patients had a previous history of using other substances of abuse, including BZDs. On the other hand, in a study by Sjögren et al., pain patients treated with pain drugs other than opi-

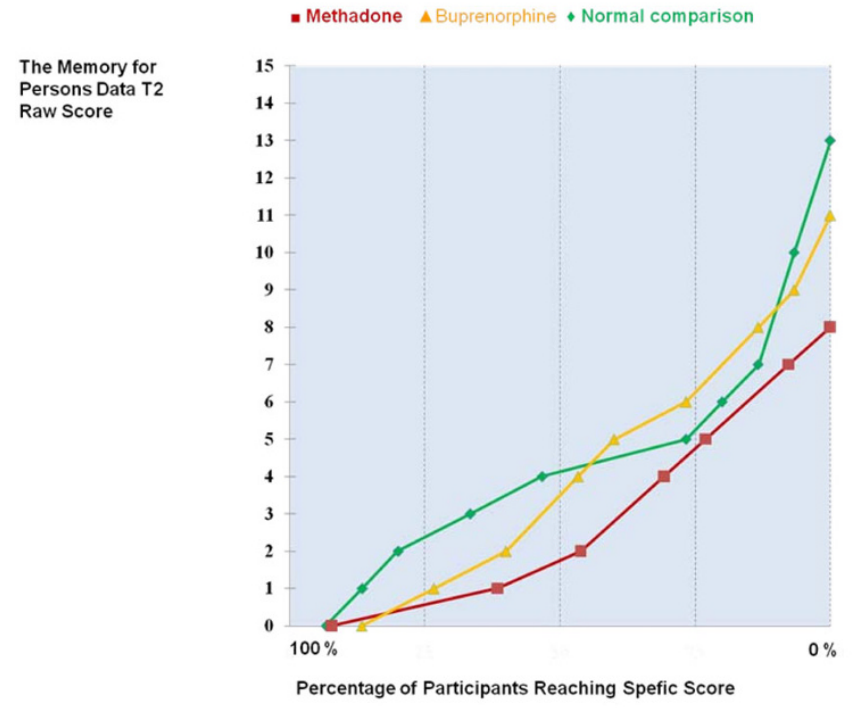

Figure 2

Cumulative percentage of the Memory for Persons Data, delayed recall (T2) scores by group. oids outperformed non-addicted opioid-treated pain patients on the PASAT [17]. In the same vein, a recent study showed that the opioid agonist morphine negatively affects working memory performance in healthy volunteers [16]. Although pure OST drug effects on working memory seem possible, the effects of OST drugs, alone or in combination with BZDs, on working memory can only be reliably examined if OST patients with and without a history of BZD use can be compared.

Our hypothesis of impaired performance in immediate verbal memory was partially confirmed as both patient groups were impaired at $\mathrm{T} 1$ in the first trial of a list learning task, the Memory for Persons Data. This finding is in line with earlier studies showing similar deficits among methadone patients $[9,43]$. However, the stability of this deficit in verbal list learning remains to be studied because the Memory for Persons Data learning task was not repeated at $\mathrm{T} 2$. Of note here is the study of Gruber et al. concerning an earlier treatment phase than was investigated in our study [14]. In their study methadonetreated patients' verbal list learning performance, improved between the first testing performed after a mean of two weeks of OST and the second after two months of treatment. However, a control group was lacking in their study. Although alternate test forms were used, practice effect in repeated verbal memory testing cannot be ruled out [44]. Thus, the evidence for early improvement of memory function is not strong.

Buprenorphine patients with concurrent BZD medication showed inferior list learning during early OST (T1). This finding is in line with a recent study by Soyka et al. in which buprenorphine patients without other dependencies were also inferior to normal comparison participants in verbal learning [45]. In a recent study by Loeber et al. no significant correlation was found between buprenorphine dose and verbal list learning performance [46]. On the other hand, Lintzeris et al. have reported that buprenorphine in combination with the BZD diazepam impairs delayed verbal memory more than buprenorphine given alone [19]. In sum, further studies of the possible "pure" buprenorphine effects or the additive negative effects of buprenorphine and BZDs on immediate verbal memory are needed.

Memory consolidation was examined by short- and longterm retention percentages. No significant group differences between patient groups and normal comparison group were observed in any condition. This is surprising because mu opioid receptor agonists and BZDs are known to negatively affect memory consolidation [47-50], However, our study is the first to study memory consolidation up to late memory consolidation that starts few hours after event occurrence $[34,35]$. Further studies are needed 
to examine if the observation of no memory consolidation impairment among OD patients is due to development of tolerance to negative effects of these drugs. There is some evidence for tolerance to methadone's long-term effects on episodic memory [51]. Tolerance for episodic memory impairing effects of BZDs, in general, are small [52], but among young individuals development of tolerance has been reported [53]. The second possible explanation for no memory consolidation impairment is that negative effects of opioids given along with BZDs may be hard to detect without a change in drug status. This means a change from a relatively highly drugged state to a low or non-drugged state or reverse. It has been reported that state change from BZD drug to placebo condition may negatively affect on memory retrieval in comparison to continuous BZD condition [54].

Analyses of long-term memory consolidation showed that among OST patients those with high memory complaints at T2 performed worse than those with low memory complaints in late memory consolidation assessed by free recall of the Memory for Persons Data items after a mean delay of six months. Of note here is the observation that there were no significant differences between high and low memory complainers on any background or other cognitive variables.

Self-rated memory problems were elevated among OD patients treated along with BZDs at both test points. Thus the patients feel that in regards to memory function their quality of life does not improve during the OST. Although OD patients often have both subjective and objective memory problems, few studies have addressed the relationship between subjective and objective memory function among patients with substance abuse problems $[13,55,56]$. In these studies patients' memory complaints have had small, if any, associations with their objective memory performance. In our study, though, moderate relationships were seen between subjective memory complaints and objective memory test performance, especially in late memory consolidation. Unfortunately, late memory consolidation deficit is not easily captured by standard neuropsychological assessment.

Methodological innovations to assess long-term memory consolidation in clinical settings are needed.

\section{Treatment and policy implications}

Working memory function is considered a gateway for problem solving in new situations, which requires fluid intelligence and executive function. Thus, when working memory capacity is low, practical reasoning tends to result in instant firm decisions that are based on readily available salient observations $[57,58]$. Among OST patients this may mean that individuals with low working memory capacity readily associate their negative sentiments with the common belief that their OST medication is "insufficient". They may feel overwhelmed if asked to consider the counterexamples that co-occurrence of medication and negative sentiments may be coincidental or that negative drug effects may be short-lived in comparison to the positive effects that will show up later.

An OST patient who is using BZD medication and who has working memory impairment may show excellent memory in one instance and very poor memory in another. The variability of a patient's performance level in rehabilitation settings or at work or school may cause confusion in the clinic and the community. To minimize this, adequate examinations should be performed, and information should be provided to the patient and his/her treatment team more frequently than is currently the case.

The results indicate that memory deficits in OST patients with current or recent BZD use are rather stable at least during the first six months of their treatment. It is possible that this is associated with OST drugs and BZDs given legally to the OD patients. However, this does not mean that OST would be harmful for the recovery of OD patients. OD patients entering OST are, in general, so stuck in the addiction, that a abstinence oriented treatment program with no opioid or BZD agonists is a realistic alternative only in rare cases $[1,4]$. Both treatment alternatives are needed, but OST should be seen as the mainstream option.

\section{Limitations}

Comparing a clinical sample of OST patients who use BZDs and other psychoactive medications against normal comparison participants imposes several limitations. Some of the patients (see Table 2), but none of the comparison participants were abusing illicit drugs. This is clear confounding factor that is difficult to eliminate when evaluating performances in memory tests. The same applies to other psychoactive medications that were legally given to some of the patients but none of the comparison participants. Thus, our results cannot be generalized to OD patients without psychoactive medications who have achieved long-term abstinence from any illicit use of drugs. Psychiatric comorbidity that included Axis I and Axis II disorders was common among patients and absent among comparison participants. A recent study by Prosser et al [59] examined correlates of cognitive function in a relatively large sample of opioid dependent patients $(n=56)$. It was found that personality pathology accounted for a greater portion of the variance in cognitive performance than any of the variables of drug use history. However, the only memory variable included in their analyses was immediate visual memory.

The mean opioid agonist doses given to our patients changed between test points, while the mean BZD doses 
and illegal substance abuse remained rather stable. The methadone dose increased from a mean of $73 \mathrm{mg}$ at T1 to $126 \mathrm{mg}$ at T2. The buprenorphine dose increased from a mean of $17 \mathrm{mg}$ at $\mathrm{T} 1$ to $23 \mathrm{mg}$ at $\mathrm{T} 2$. Thus, dose change and time factors are both affecting the results, and with our study design, separating these effects is not possible. The buprenorphine group included both buprenorphineonly and buprenorphine/naloxone patients. This was partially a practical issue because the majority of buprenorphine patients in Finland have been transferred to buprenorphine-naloxone combination medication. There is no evidence that sublingual naloxone exhibits opioid antagonist activity or would interfere with the opioid agonist effects of buprenorphine $[26,60]$. However, because there are no studies directly comparing buprenorphineonly and buprenorphine/naloxone patients, combining these patients can be considered a limitation of our study. The list learning task (the Memory for Persons Data) was not repeated at T2, which poses a limitation for the analyses of immediate verbal memory. Psychoactive drugs, such as short-acting non-BZDs, neuroleptics, or opioid withdrawal relievers, were given to both patient groups in order to alleviate opioid withdrawal symptoms or to treat psychiatric comorbidity. The possible interactions of OST medications with these medications warrant further studies with larger sample sizes. Recent-month drug screens were considered important because it is known that longterm use of benzodiazepines or cannabis may have a negative impact on cognitive function even weeks after cessation of use $[18,61]$. However, our data cannot determine the precise doses used during the recent month, nor does the data cover full time span of the follow-up. Thus, the results do not reflect "pure" drug effects of OST drugs and BZDs. On the other hand, no major differences between the substance abuse profiles of methadone and buprenorphine patients were seen. OD patients may differ from the general population already in their premorbid cognitive functioning [62]. Screening for premorbid conduct or attention deficit disorder could possibly reveal interactions with current cognitive functions among OST patients $[63,64]$. However, retrospective assessment of these has low reliability in the absence of longitudinal records [65]; therefore, these assessments were not done in our study. Finally, our sample size was relatively small, and therefore type 2 errors cannot be excluded.

\section{Conclusion}

OD patients treated with methadone or buprenorphine along with BZDs showed substantial deficits in working memory both during beginning of the treatment, and after six months of treatment. Given the previously stated limitations of this study, we conclude that OD patients taking opioid agonist drugs and BZDs score worse than normal comparison persons in tests of memory during first six months of their OST. Thus, it is possible that the working memory deficit observed among these patients might be relatively permanent. An immediate verbal memory deficit may also be seen among them. Surprisingly, there were no significant memory consolidation differences between the patient groups and normal comparison group. On the other hand, OST patients reported subjective memory problems that were associated with poor late memory consolidation. This has obvious functional relevance for the patients. Therefore, we propose that the relationship between subjective and objective memory function should be taken into account in longitudinal studies of substance abuse treatment and clinical practice.

\section{Competing interests}

The authors declare that they have no competing interests.

\section{Authors' contributions}

PR planned and performed cognitive testing and statistical analysis. He wrote the first version of the manuscript and prepared the final manuscript. HA conceived the idea of the study and advised in manuscript preparation. HK participated in the design of the study and in manuscript preparation. CF carried out psychiatric investigations. All authors prepared, read and accepted the final manuscript.

\section{Acknowledgements}

This work was funded by the Finnish National Public Health Institute (KTL), the Yrjö Jahnsson Foundation, the Rauha and Jalmari Ahokas Foundation, the Emil Aaltonen Foundation, and the Psychiatry Department of Helsinki University Central Hospital. We thank Mikko Salaspuro, Veijo Virsu, and Kristian Wahlbeck for helpful comments during the research process, and Pertti Keskivaaara and Jari Lipsanen for statistical advice. The authors are grateful to the patients and personnel of the clinics who participated in the study.

\section{References}

I. Amato L, Davoli M, Perucci CA, Ferri M, Faggiano F, Mattick RP: An overview of systematic reviews of the effectiveness of opiate maintenance therapies: available evidence to inform clinical practice and research. Journal of Substance Abuse Treatment 2005 , 28:32I-329.

2. Connock M, Juarez-Garcia A, Jowett S, Frew E, Liu Z, Taylor R, FrySmith A, Day E, Lintzeris N, Roberts T, Burls A, Taylor RS: Methadone and buprenorphine for the management of opioid dependence: a systematic review and economic evaluation. Health Technology Assessment 2007, I I:I.

3. Amato L, Minozzi S, Davoli M, Vecchi S, Ferri MMF, Mayet S: Psychosocial combined with agonist maintenance treatments versus agonist maintenance treatments alone for treatment of opioid dependence. Cochrane Database Syst Rev 2008:CD004 I 47.

4. Mattick RP, Kimber J, Breen C, Davoli M: Buprenorphine maintenance versus placebo or methadone maintenance for opioid dependence. Cochrane Database Syst Rev 2003, 2:

5. Fischer B, Rehm J, Kim G, Kirst M: Eyes wide shut?-A conceptual and empirical critique of methadone maintenance treatment. Eur Addict Res 2005, I I: I- | 4 .

6. Dursteler-MacFarland KM, Stohler R, Moldovanyi A, Rey S, Basdekis $R$, Gschwend P, Eschmann S, Rehm J: Complaints of heroin-maintained patients: A survey of symptoms ascribed to diacetylmorphine. Drug Alcohol Depend 2006, 8 I (3):23 I-239.

7. Veide N, Alaja R, Seppä K: Millaisia ovat potilaat opioidiriippuvuuden hoito-ohjelmassa [Characteristics of patients treated 
in opioid-substitution programs]. Suomen laakaril 2007 , 62:1964-1966.

8. Vorma H, Sokero P, Turtiainen S, Katila H: Opioidikorvaushoito Tehoaa. Korvaushoito Hyksin päihdepsykiatrian yksikössä 2000-2002. [Opioid substitution treatment in 2000-2002 at the Psychiatric Unit for Drug Dependence of the Helsinki University Central Hospital (HUCH)]. Suomen laakaril 2005, 60:1013-1016

9. Darke S, Sims J, McDonald S, Wickes W: Cognitive impairment among methadone maintenance patients. Addiction 2000, 95:687-695.

10. Davis PE, Liddiard H, McMillan TM: Neuropsychological deficits and opiate abuse. Drug Alcohol Depend 2002, 67:105-108.

II. Mintzer MZ, Correia CJ, Strain EC: A dose-effect study of repeated administration of buprenorphine/naloxone on performance in opioid-dependent volunteers. Drug Alcohol Depend 2004, 74(2):205-209.

12. Pirastu R, Fais R, Messina M, Bini V, Spiga S, Falconieri D, Diana M Impaired decision-making in opiate-dependent subjects: Effect of pharmacological therapies. Drug Alcohol Depend 2006, 83:163-168

13. Grevert P, Masover B, Goldstein A: Failure of methadone and levomethadyl acetate (levo-alpha-acetylmethadol, LAAM) maintenance to affect memory. Arch Gen Psychiatry 1977, 34:849-853.

14. Gruber SA, Tzilos GK, Silveri MM, Pollack M, Renshaw PF, Kaufman MJ, Yurgelun-Todd DA: Methadone Maintenance Improves Cognitive Performance After Two Months of Treatment. Exp Clin Psychopharmacol 2006, I4:157-164.

15. Rapeli P, Fabritius C, Alho H, Salaspuro M, Wahlbeck K, Kalska H: Methadone vs. buprenorphine/naloxone during early opioid substitution treatment: a naturalistic comparison of cognitive performance relative to healthy controls. BMC Clin Pharmacol 2007, 7:5.

16. Friswell J, Phillips C, Holding J, Morgan CJ, Brandner B, Curran HV: Acute effects of opioids on memory functions of healthy men and women. Psychopharmacology (Berl) 2008, 198(2):243-50. Epub 2008 Apr I.

17. Sjogren P, Christrup LL, Petersen MA, Hojsted J: Neuropsychological assessment of chronic non-malignant pain patients treated in a multidisciplinary pain centre. Eur J Pain 2005, 9(4):453-462.

18. Barker MJ, Greenwood KM, Jackson M, Crowe SF: Persistence of cognitive effects after withdrawal from long-term benzodiazepine use: a meta-analysis. Arch Clin Neuropsychol 2004 19:437-454

19. Lintzeris N, Mitchell TB, Bond A, Nestor L, Strang J: Interactions on mixing diazepam with methadone or buprenorphine in maintenance patients. J Clin Psychopharmacol 2006, 26:274-283.

20. Crook TH 3rd, Feher EP, Larrabee GJ: Assessment of memory complaint in age-associated memory impairment: the MACQ. Int Psychogeriatr 1992, 4:165-176.

21. First MB, Spitzer RL, Gibbon M, Williams JBM: Structured clinical interview diagnostic (SCID) for DSM-IV axis I disorders-clinician version (SCID-CV). 1997.

22. First MB, Spitzer RL, Gibbon M, Williams JBW, Benjamin L: Structured clinical interview for DSM-IV Axis II personality disorders (SCID-II). Version 2.0. New York State Psychiatric Institute; 1994

23. Koob GF: Drugs of abuse: anatomy, pharmacology and function of reward pathways. Trends Pharmacol Sci 1992, I3:177-184.

24. Compton P, Ling W, Chiang CN, Moody DE, Huber A, Ling D, Charuvastra C: Pharmacokinetics of buprenorphine: $A$ comparison of sublingual tablet versus liquid after chronic dosing. Journa of Addiction Medicine 2007, I:88-95.

25. Harris DS, Mendelson JE, Lin ET, Upton RA, Jones RT: Pharmacokinetics and subjective effects of sublingual buprenorphine, alone or in combination with naloxone - Lack of dose proportionality. Clin Pharmacokinet 2004, 43:329-340.

26. Ciraulo DA, Hitzemann RJ, Somoza E, Knapp CM, Rotrosen J, SaridSegal O, Ciraulo AM, Greenblatt DJ, Chiang CN: Pharmacokinetics and pharmacodynamics of multiple sublingual buprenorphine tablets in dose-escalation trials. Journal of Clinical Pharmacology 2006, 46: 179-192.

27. Ashton $\mathrm{H}$ : The diagnosis and management of benzodiazepine dependence. Curr Opin Psychiatry 2005, 18:249-255.
28. Baddeley A: Working memory: looking back and looking forward. Nat Rev Neurosci 2003, 4:829-839.

29. Wecshler D: Wechsler Memory Scale - Revised (WMS-R). Finnish version Helsinki: Psykologien kustannus; 1996.

30. Gronwall DM: Paced auditory serial-addition task: a measure of recovery from concussion. Percept Mot Skills 1977, 44:367-373.

3I. Koskinen SK, Sarajuuri JM: Computer-administered cognitive remediation in a frame of holistic neuropsychological rehabilitation: FORAMENrehab programs. Acta Neurochir (Wien) 2002, I44:A20-A2I.

32. Talmi D, Grady CL, Goshen-Gottstein Y, Moscovitch M: Neuroimaging the serial position curve - $A$ test of single-store versus dual-store models. Psychological Science 2005, 16:716-723.

33. Kaitaro T, Koskinen S, Kaipio ML: Neuropsychological problems in everyday life: a 5-year follow-up study of young severely closed-head-injured patients. Brain Inj 1995, 9:713-727.

34. Dudai $Y$ : The neurobiology of consolidations, or, how stable is the engram? Annu Rev Psychol 2004, 55:5I-86.

35. Izquierdo I, McGaugh JL: Behavioural pharmacology and its contribution to the molecular basis of memory consolidation. Behavioural Pharmacology 2000, I I:5 17-534.

36. Huron C, Giersch A, Danion JM: Lorazepam, sedation, and conscious recollection: a dose-response study with healthy volunteers. Int Clin Psychopharmacol 2002, 17:19-26.

37. Alexander JRM, Smales S: Intelligence, learning and long-term memory. Pers Individ Dif 1997, 23:8I5-825.

38. Holm S: A simple sequentially rejective multiple test procedure. Scand Stat Theory Appl 1979, 6:1979.

39. Coe R: pp. Microsoft Excel spreadsheet. The Curriculum, Evaluation and Management Centre, Durham University, UK; 2000.

40. Effect Size Calculator [http://www.cemcentre.org/renderp age.asp?linkID=303250I7]

4I. Verdejo A, Toribio I, Orozco C, Puente KL, Perez-Garcifa M: Neuropsychological functioning in methadone maintenance patients versus abstinent heroin abusers. Drug Alcohol Depend 2005, 78:283-288.

42. Mintzer MZ, Stitzer ML: Cognitive impairment in methadone maintenance patients. Drug Alcohol Depend 2002, 67:4I-5I.

43. Curran HV, Kleckham J, Bearn J, Strang J, Wanigaratne S: Effects of methadone on cognition, mood and craving in detoxifying opiate addicts: a dose-response study. Psychopharmacology (Berl) 200I, I 54:153-160.

44. Uchiyama CL, Delia LF, Dellinger AM, Becker JT, Selnes OA, Wesch JE, Chen BB, Satz P, Vangorp W, Miller EN: Alternate Forms of The Auditory-Verbal Learning Test - Issues of Test Comparability, Longitudinal Reliability, and Moderating Demographic-Variables. Arch Clin Neuropsychol 1995, 10:133-145.

45. Soyka MMD, Lieb MMD, Kagerer SP, Zingg CM, Koller GMD, Lehnert PMD, Limmer CMD, Kuefner HP, Hennig-Fast KP: Cognitive Functioning During Methadone and Buprenorphine Treatment: Results of a Randomized Clinical Trial. Journal of Clinical Psychopharmacology 2008, 28:699-703

46. Loeber S, Kniest A, Diehl A, Mann K, Croissant B: Neuropsychological Functioning of Opiate-Dependent Patients: A Nonrandomized Comparison of Patients Preferring either Buprenorphine or Methadone Maintenance Treatment. Am J Drug Alcohol Abuse 2008, 34(5):584-593.

47. McGaugh JL, Cahill L, Roozendaal B: Involvement of the amygdala in memory storage: Interaction with other brain systems. Proc Natl Acad Sci 1996, 93: I3508-I35I4.

48. Curran HV: Tranquillising memories: A review of the effects of benzodiazepines on human memory. Biological Psychology 1986, 23:179-213.

49. Guarna M, Ghelardini C, Galeotti N, Bartolini A, Noli L, Neri C, Stefano GB, Bianchi E: Effects of endogenous morphine deprivation on memory retention of passive avoidance learning in mice. Int / Neuropsychopharmacol 2004, 7:3| I-319.

50. Schneider U, Bevilacqua C, Jacobs R, Karst M, Dietrich DE, Becker H, Müller-Vahl KR, Seeland I, Gielsdorf D, Schedlowski M, Emrich HM: Effects of Fentanyl and Low Doses of Alcohol on Neuropsychological Performance in Healthy Subjects. Neuropsychobiology 1999, 39:38-43.

51. Curran HV, Bolton J, Wanigaratne S, Smyth C: Additional methadone increases craving for heroin: a double-blind, placebocontrolled study of chronic opiate users receiving methadone substitution treatment. Addiction 1999, 94:665-674. 
52. Curran HV: Effects of anxiolytics on memory. Human Psychopharmacology-Clinical and Experimental 1999, 14:S72-S79.

53. Roybyrne P, Fleishaker J, Arnett C, Dubach M, Stewart J, Radant A, Veith R, Graham M: Effects of Acute and Chronic Alprazolam Treatment on Cerebral Blood-flow, Memory, Sedation, and Plasma-catecholamines. Neuropsychopharmacology 1993, 8:161-169.

54. File SE, Goodall EM, Mabbutt PS, Harris A, Skelly AM: Statedependent retrieval and midazolam. Human Psychopharmacology: Clinical and Experimental 1993, 8:.

55. Fals-Stewart W: Ability to counselors to detect cognitive impairment among substance-abusing patients: an examination of diagnostic efficiency. Exp Clin Psychopharmacol 1997, 5:39-50.

56. Horner MD, Harvey RT, Denier CA: Self-report and objective measures of cognitive deficit in patients entering substance abuse treatment. Psychiatry Res 1999, 86:155-161.

57. De Neys W, Schaeken W, d'Ydewalle G: Working memory and everyday conditional reasoning: Retrieval and inhibition of stored counterexamples. Thinking \& Reasoning 2005, I I:349-38 I.

58. Wim De N: Dual Processing in Reasoning. Psychological Science 2006, 17:428-433.

59. Prosser J, Eisenberg D, Davey E, Steinfeld M, Cohen L, London E, Galynker I: Character pathology and neuropsychological test performance in remitted opiate dependence. Substance Abuse Treatment, Prevention, and Policy 2008, 3:23.

60. Elkader A, Sproule B: Buprenorphine: Clinical Pharmacokinetics in the Treatment of Opioid Dependence. Clinical Pharmacokinetics 2005, 44:66I.

61. Solowij N, Battisti R: The Chronic Effects of Cannabis on Memory in Humans: A Review. Curr Drug Abuse Rev 2008, I:8I-98.

62. Weiser M, Reichenberg A, Rabinowitz J, Knobler HY, Lubin G, Yazvitzky R, Nahon D, Gur RC, Davidson M: Cognitive performance of male adolescents is lower than controls across psychiatric disorders: a population-based study. Acta Psychiatrica Scandinavica 2004, I I0:47। -475.

63. Brooks DJ, Vosburg SK, Evans SM, Levin FR: Assessment of cognitive functioning of methadone-maintenance patients: Impact of adult ADHD and current cocaine dependence. Journal of Addictive Diseases 2006, 25:15-25.

64. Giancola PR, Mezzich AC: Neuropsychological deficits in female adolescents with a substance use disorder: Better accounted for by conduct disorder? Journal of Studies on Alcohol 2000, 61:809-8I7.

65. Levin FRDx: Diagnosing attention-deficit/hyperactivity disorder in patients with substance use disorders. Journal of Clinical Psychiatry 2007, 68:9-14.
Publish with Bio Med Central and every scientist can read your work free of charge

"BioMed Central will be the most significant development for disseminating the results of biomedical research in our lifetime. "

Sir Paul Nurse, Cancer Research UK

Your research papers will be:

- available free of charge to the entire biomedical community

- peer reviewed and published immediately upon acceptance

- cited in PubMed and archived on PubMed Central

- yours - you keep the copyright
BioMedcentral 